\title{
Comparing the effects of release methods on survival of the Eurasian black vulture Aegypius monachus reintroduced in France
}

\author{
Jean-Baptiste Minoub, Karine Princé, Olivier Duriez, Philippe Lécuper \\ BERTRAND ELIOTOUT and FranÇOIS SARRAZIN
}

\begin{abstract}
The Near Threatened Eurasian black vulture Aegypius monachus is considered highly threatened in Europe, and the species was reintroduced in France between 1992 and 2004. A total of 53 individuals were released, using two methods: immatures were released from large aviaries at the reintroduction site after a stay of several months (the aviary method), whereas juveniles were placed on artificial nests until fledging (the hacking method). The survival rates of released birds were compared to the survival of wildborn offspring through a multi-event capture-recapture analysis accounting for tag loss. Survival rates were higher in adults than in juveniles and immatures (0.98 \pm SE 0.02 vs $0.85 \pm \mathrm{SE} 0.03)$ and were constant over time. Overall there were no differences in post-release survival between the two release methods: immatures released by the aviary method had a similar survival to juveniles released by the hacking method or born in the wild. Immatures can breed before juveniles, so releasing immatures by the aviary method could accelerate reintroduction settlement and increase population viability. Accurate estimates of post-release survival are essential to improve the reliability of viability analysis of reintroduced populations and the management of such populations.
\end{abstract}

Keywords Bird translocation, demography, Eurasian black vulture, founder effect, France, multi-event capturerecapture analysis, raptor conservation

This paper contains supplementary material that can be found online at http://journals.cambridge.org

Jean-Baptiste Minoub (Corresponding author), Karine Princé, Olivier DURIEZ ${ }^{*}$ and FranCOIS SARRAZIN UPMC Univ 06, UMR 7204, MNHN-CNRSUPMC 'Conservation des Espèces, Restauration et Suivi des Populations', CP 51, 55 rue Buffon, F-75005 Paris, France. E-mail mihoub@mnhn.fr

Philippe Lécuyer and Bertrand Eliotout LPO Grands Causses, Le Bourg, 12720 Peyreleau, France

*Also at: Centre d'Ecologie Fonctionnelle et Evolutive, Université Montpellier 2, Montpellier, France

Received 16 December 2011. Revision requested 13 March 2012. Accepted 18 June 2012. First published online 7 November 2013.

\section{Introduction}

$\mathrm{R}$ eintroductions are increasingly used to restore species Rout there are many challenges in the establishment of self-sustaining populations (Sarrazin, 2007; Armstrong \& Seddon, 2008). Researchers and managers need to assess the success of reintroductions as soon as possible after releases, for example by examining demographic and behavioural features of founders and their wild-born offspring. Survival is a major component of population viability, particularly for long-lived species (Lebreton \& Clobert, 1991), and thus estimation of post-release survival in the release area is required (Armstrong \& Seddon, 2008). Post-release survival may be affected by release and rearing methods, age and sex-ratio of the released stock, time spent in captivity and inexperience in the wild (Hardman \& Moro, 2006).

To account for age-related specificities animals can be released using various methods. In raptors, juveniles are usually released by hacking (Dzialak et al., 2006), which involves placing chicks in artificial nests and providing them with the required care until they fledge. Fledged birds can be released immediately upon transport to the release site or after a transition period in cages (Wolf et al., 1996). Assessing the outcomes of different release methods may aid the adaptive design of release guidelines for species with similar life-histories.

To assess the relevance of release strategies demographic parameters of reintroduced populations, obtained by monitoring released individuals, should be analysed as soon as appropriate data have been collected (Sarrazin \& Legendre, 2000). Ideally, the effect of release methods on survival should be assessed by comparing survival of released vs wild-born individuals in the same environment (Sarrazin et al., 1994; Nicoll et al., 2004; Brown et al., 2006; Evans et al., 2009). The monitoring of bird reintroductions is insufficient in many cases (Sutherland et al., 2010) and therefore assessment of post-release survival is of particular interest.

We aimed to test the effect of two release methods on survival, using observations of Eurasian black vultures Aegypius monachus reintroduced in France. After extirpation in France the species was reintroduced in the Grands Causses, in the south, between 1992 and 2005. The hacking method was used for juveniles, and immatures were released after spending at least 1 year in aviaries at the release site. 
Both methods involved imprinting periods and were considered to be so-called soft releases. The release programme in the Grands Causses has now finished but two reintroduction programmes continue in the French southern Alps. Following previous findings of post-release cost on survival in raptors (Sarrazin et al., 1994; Brown et al., 2006; Evans et al., 2009) we suspected that released birds would have a short-term decrease in survival after release compared to wild-born individuals. However, it was unclear whether the release method (hacking vs aviary) affects survival. We therefore compared survival rates of birds released by the two methods with the survival of wild-born individuals. Annual survival probabilities were estimated with capture-recapture survival analysis, using 16 years of resighting-recovery data. The multi-event framework was used to test biological hypotheses about survival (e.g. age, time or release effects) while accounting for tag loss, which could be significant in long-lived raptors (Tavecchia et al., 2011).

\section{Species and study site}

The distribution range of the black vulture extends from the Iberian Peninsula to Mongolia and Russia (del Hoyo et al., 1996). The species is categorized as Near Threatened on the IUCN Red List (BirdLife International, 2012), and disappeared from France at the beginning of the 2oth century. Following the reintroduction of the griffon vulture Gyps fulvus in 1981-1986 in the Grands Causses, southern France (Fig. 1; Sarrazin et al., 1994), a reintroduction programme was conducted for black vultures. Between 1992 and 2004 30 immature and 23 juvenile black vultures, from rescue centres and zoos, were released (Fig. 2). Releases from aviaries occurred from January to November, whereas the release of juveniles by the hacking method followed the phenology of wild fledglings (i.e. between late July and early September). The aviary birds were $2-4$ years old at release but most were released in their second year $(n=17 ; 56 \%$; mean age at release $=2.04 \pm \mathrm{SE} 0.91$ years $)$. We therefore considered time since release rather than biological age in our analysis (but see Sarrazin et al., 1994). By 200847 juveniles had fledged in the wild since the first wild chick was born in 1996.

\section{Methods}

\section{Banding and monitoring}

Black vultures were tagged with an engraved metal band attached to one tarsus (provided by the French banding centre, CRBPO, Paris) and a plastic band to facilitate longdistance identification on the other tarsus. Metal bands could only be read at $<50 \mathrm{~m}$, by telescope. Two kinds of plastic bands were used: a combination of four coloured

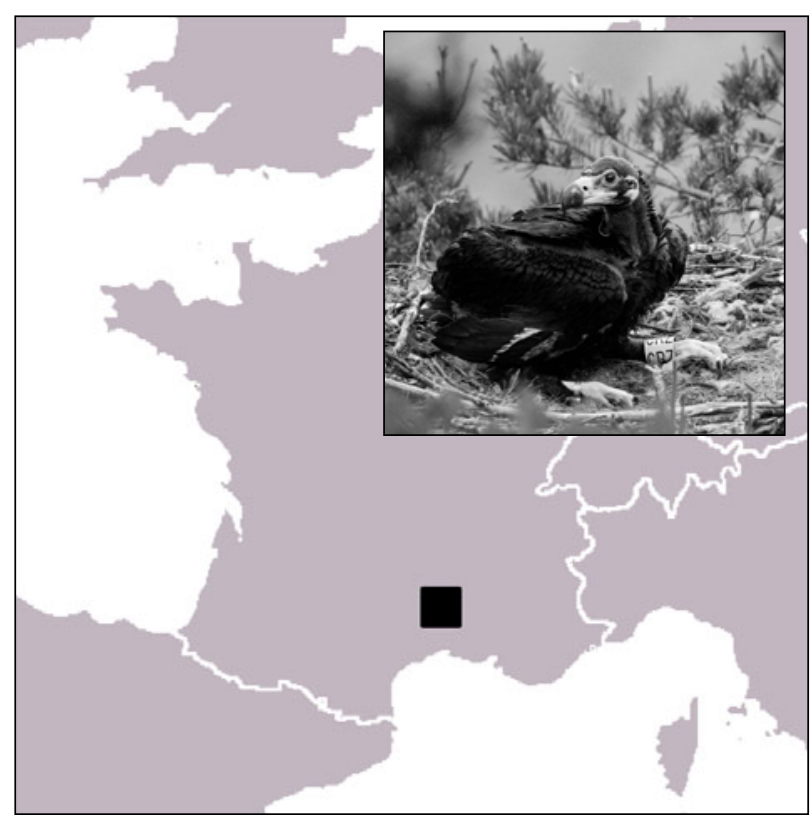

FIG. 1 The location of the study area (shaded rectangle) in the Grands Causses region of southern France. The inset shows a wild-born Eurasian black vulture Aegypius monachus on its nest in the Grands Causses after tagging, with a lettered plastic band on the left tarsus and a metal band on the right tarsus.

bands (hereafter 'coloured') for reintroduced birds, and a white band engraved with black letters ('lettered') for wildborn individuals. In addition to coloured bands, aviaryreleased immatures were equipped with radio-transmitters that have a battery life of 1 year. We considered all observations and recoveries of the 47 wild-born and 53 reintroduced individuals from 1992 to 2008. Black vultures were identified throughout the year using telescopes. Plastic bands could be lost as birds aged (14 live birds were only identifiable from their metal bands). The coloured bands were thinner than lettered bands and we therefore suspect there was a higher rate of loss of the former. Consequently, we explicitly considered the loss of plastic bands, to avoid bias (Kendall et al., 2006).

\section{Capture-recapture analysis}

Capture-recapture analyses are used to estimate survival rates (Lebreton et al., 1992). Although an important assumption is that resighting periods should be short compared to the time interval between two resighting sessions (Nichols, 1992), long resighting sessions may not necessarily bias parameter estimates and can improve precision by allowing more individuals to be identified (O’Brien et al., 2005). We therefore only used observations from a 9-month period (1 January-30 September; the same as that used by Sarrazin et al., 1994, and Le Gouar et al., 2008). The use of recoveries and resighting data produced more robust and precise estimates (Barker, 1997; Kendall et al., 2006). An individual was considered 'resighted alive' if 
(a)

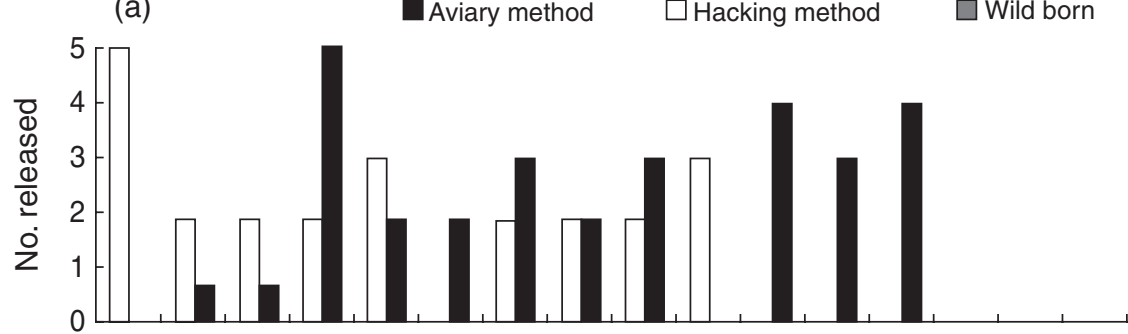

(b)

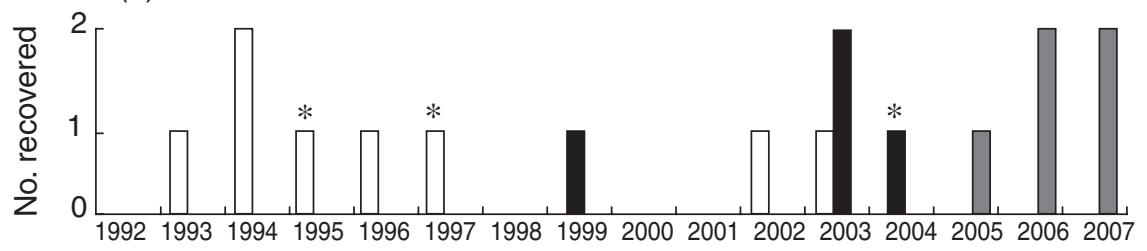

FIG. 2 The number of reintroduced black vultures that were banded and released (a) and recovered dead (b) in the Grands Causses region (Fig. 1). Individuals were released from 1992 to 2004, using either the aviary method, for immature birds, or the hacking method, for captivereared juveniles on artificial nests (see text for further details). ${ }^{\star}$ Birds unable to survive in the wild and permanently recaptured (considered as dead in the analyses). seen alive at least once during the resighting period; 'dead recoveries' consisted of birds found dead at any time. We did not use resighting observations outside the study area, even if some birds demonstrated long-range dispersal.

In the classical Cormack-Jolly-Seber capture-recapture model all individuals have equal probabilities of survival and being resighted (Lebreton et al., 1992). This assumption is not met when tag loss occurs, which could lead to an underestimate of survival (Lebreton et al., 1992; Tavecchia et al., 2011). Tag loss and survival were considered as two successive steps (i.e. events), with tag loss being estimated prior to survival (Grosbois \& Tavecchia, 2003). Survival rates were estimated using the transitions from 'alive states' to 'newly dead states' (Lebreton \& Pradel, 2002). To separate tag loss from mortality we explicitly described two resighting events for individual capture-recapture histories, using a multi-event structure (Pradel, 2005; Kendall et al., 2006; Le Gouar et al., 2008). Individuals were coded in two states (alive or dead), whereas resightings of metal and plastic bands were considered as two events of the alive state (Fig. 3; Supplementary Material 1). Resightings of plastic or metal bands were coded as events 1 and 2, respectively, and the newly dead states (recoveries) were coded as 3. For example, 11102300 described the capture history of a bird initially banded with a plastic band released at occasion 1 and seen at occasions 2 and 3 with this marking, not seen at occasion 4, identified with its metal band at occasion 5 (i.e. plastic band loss), and finally recovered dead at occasion 6. When dealing with both resighting and recovery data an individual banded (or resighted alive) and found dead on the same occasion poses a problem. Each individual can have only one 'event' per occasion in the capture-recapture history structure. Therefore, we systematically postponed all dead events to the next occasion. Survival was probably slightly overestimated but the potential bias was similar for all groups (Duriez et al., 2009, 2012). The two plastic bands

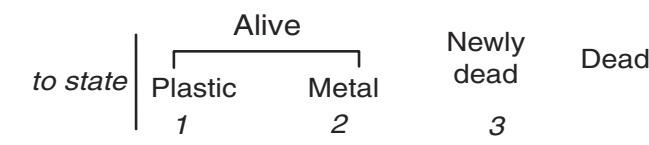

$\begin{array}{cc}\text { Alive } \\ \begin{array}{c}\text { Newly dead } \\ \text { Detal }\end{array} & 2 \\ \text { Dead } & 3\end{array}\left(\begin{array}{cccc}\Psi^{11} \Phi & \left(1-\Psi^{11}\right) \Phi & (1-\Phi) & 0 \\ 0 & \Phi & (1-\Phi) & 0 \\ 0 & 0 & 0 & 1 \\ 0 & 0 & 0 & 1\end{array}\right)$

FIG. 3 Schematic matrix framework used in the multi-event capture-recapture analysis, including survival $(\Phi)$ and tag loss $(\Psi)$ probabilities. Survival probability was independent of banding status and there were therefore no state-specific indices on parameter $\Phi$. The probability of retaining a metal band $\left(\Psi^{22}\right)$ was assumed to be 1 because of the high persistence of such bands. As no remarking event that would enable transition from state 2 to state 1 occurred, $\Psi^{21}$ was fixed at 0.

(coloured and lettered) may have aged differently, possibly leading to different probabilities of tag loss. We assigned a group label (i.e. a permanent individual attribute) to each kind of plastic band. Since reintroduced and wild-born individuals bear coloured and lettered bands, respectively, band group designation was equivalent to distinguishing wild-born from reintroduced individuals (tag loss notation: band; Table 1).

To compare survival between release methods we split the group 'coloured' (i.e. all released black vultures) into two groups with respect to the release method (hacking vs aviary). Three groups were then used to run the analysis: the aviary group and the hacking group, wearing coloured bands, and the wild-born group, wearing lettered bands (Table 1). We used E-Surge to perform multi-event capturerecapture analysis (Choquet et al., 2008). We used the general model and parameter notations given by Lebreton 
TABLE 1 Notation and biological definition of the hypotheses tested in the capture-recapture analysis of the effects of release methods on survival of the Eurasian black vulture Aegypius monachus reintroduced in France. As we assumed a constant recovery of dead individuals, this parameter is not presented. Interactions with time ${ }^{\star} t$ (e.g. $a^{\star} t$ ) were tested but for simplicity are not presented here.

\begin{tabular}{ll}
\hline Notation & Definition and hypothesis \\
\hline Survival $(\boldsymbol{\Phi})$ & Constant (no age, no time and no release effect) \\
$i$ & Time effect only \\
$t$ & Release method effect only (aviary released immatures vs hacking-released \& wild-born juveniles) \\
method & Reintroduction effect only (released vs wild-born) \\
reintro & Age effect only (two age classes; 1 -4 years vs $\geqslant 5$ years) \\
$a$ & Age effect \& short-term release method effect for aviary-released immatures (survival similar to hacking-released \\
$a^{*}$ method,s & \& wild-born juveniles) \\
$a^{*}$ method, $d$ & Age effect \& short-term release method effect for aviary-released immatures (survival different from \\
& hacking-released \& wild-born juveniles) \\
$a^{*}$ reintro & Age effect \& short-term reintroduction effect for aviary-released immatures (reintroduced vs wild-born) \\
Encounter probabilities: resight (P) and recovery (r) \\
$i$ & Constant (no time effect) \\
$t, p$ & Time effect on resighting plastic band only \\
$t, m$ & Time effect on resighting metal band only \\
$t$, both & Time effect on resighting both metal \& plastic band \\
Tag loss $(\boldsymbol{\Psi})$ & Constant (no age \& no band effect) \\
$i$ & Band effect only (different probabilities of losing coloured \& lettered bands) \\
band & Age effect only (the 3 first years vs $\geqslant 4$ years) \\
age & Interaction of age \& band effect \\
band &
\end{tabular}

et al. (1992): apparent annual survival probability $(\Phi)$, resighting and dead recovery probabilities ( $\mathrm{P}$ and $r$, respectively), and transition probability ( $\Psi$, corresponding here to tag loss) allowing an individual to 'move' from one state to another conditionally upon survival. The capturerecapture multi-event structure allowed for simultaneous estimates of $\Phi, P, r$ and $\Psi$ (full details in Supplementary Material 2). Notation of the hypothesis tested for a given parameter is indicated as an index (e.g. $\Phi_{i}$ for constant survival). Interactions are noted with ${ }^{*}$. We used Akaike's information criterion (AIC) for model selection, using AICc (i.e. AIC corrected for small sample sizes; Burnham \& Anderson, 2002). We performed a stepwise model selection considering $\triangle \mathrm{AICc}<2$ as a criterion for assessing statistical difference in inferences tested (Lebreton et al., 1992). However, differences up to 4-7 points in AICc scores could indicate statistical equivalence (Burnham \& Anderson, 2002). Therefore we finally considered model selection uncertainty using model-averaged estimates and AICc weight among all models remaining within $\triangle \mathrm{AICc}=7$. Parameters were estimated using the logit link function and estimates are given as mean \pm SE (Choquet et al., 2005).

\section{Goodness-of-fit}

Goodness-of-fit tests facilitate detection of poor fits to the data, which could inflate model deviances, bias estimates or produce incorrect model selections (Pradel et al., 2005).
Adequate goodness-of-fit tests are currently lacking for a mix of live and dead states (Pradel et al., 2005). We therefore performed two separate tests, using either resighting observations (goodness-of-fit-live) or recoveries (goodness-of-fit-dead; Duriez et al., 2009). For the former we removed the dead state from the data set. For the latter we only kept the first occasion and the dead recovery event (all resightings were replaced with o). This approach allows interpreting TEST M components (usually used to detect trap-dependence) as a test for transience in dead recoveries (Pradel et al., 2005). All goodness-of-fit tests were performed with U-CARE 2.5 (Choquet et al., 2005).

\section{Selection of biological hypotheses}

Exhaustive testing for all possible combinations of time, age, release method and banding group on parameters $\Phi, P$, $r$ and $\Psi$ would require running hundreds of models given the size of our data set. We therefore only examined biologically pertinent inferences. It seemed unlikely that banding status would affect survival and we therefore assigned identical survival probabilities irrespective of banding status. As a new band may be more persistent than an old one we tested age-dependence on tag loss probabilities $\left(\Psi^{12}\right)$. Using field observations we compared tag loss during the first 3 years to losses in later years (transition notation age; Table 1). We tested for potential difference in loss rates between coloured and lettered bands 
using a group effect on $\Psi^{12}$. We assumed that metal bands cannot be lost ( $\Psi^{22}$ fixed to 1; Fig. 3). As the first reading of a metal band was in 1998 we fixed the metal band detection probability at zero before this occasion, and allowed tag loss (i.e. $\Psi^{12}$; Supplementary Material 2) before 1998. As the effort in recovering dead vultures was fairly constant throughout the monitoring, time dependence was tested only on resighting probabilities. Nevertheless, recoveries of aviary-released birds might have been higher during the first year after release because they carried radio-transmitters and so we considered age-dependence (first year vs older) in their recovery probabilities. Otherwise, recovery probabilities were considered constant over time and equal between groups. Radio-tracking might have generated higher detection probabilities than the band reading used for resighting probabilities. Therefore radio-tracking data were only used for the recovery probabilities of the dead state and were discarded for the alive state when coding recapture histories, to avoid confusion with resighting through band reading.

Long-lived raptors generally demonstrate several specific life stages: a progressive independence during the first year of life, followed by the prospecting vagrant behaviour of immatures and lastly a breeding adult stage. Before testing inferences on post-release survival we ran preliminary analyses to determine the most likely agestructured survival related to these life stages. Based on previous findings for vulture species (Sarrazin et al., 1994; Oro et al., 2008; Schaub et al., 2009) and on our knowledge of the species, we examined four hypotheses of age structure (Supplementary Table S1). We tested either constant or time-dependent survival using full time-dependent resighting probabilities $\left(\mathrm{P}_{t, \text { both }}\right)$ and full parameterized tag loss pattern ( $\Psi_{\text {band*age; }}$ Supplementary Table $\left.\mathrm{S} 1\right)$. Similar to Oro et al. (2008) we identified two age classes: juveniles and immatures ( $1-4$ years of age) and adults $>4$ years old ( $a 4-5$, Supplementary Table $\mathrm{S}_{2}$ ). We retained this age-structured survival, denoting it simply as $a$, to simplify notation. Sex was not considered because the black vulture is a monomorphic species that does not demonstrate differences in foraging or breeding behaviours between the sexes, similar to griffon vultures (Bose et al., 2007).

To investigate the effect of release method on survival we distinguished three main hypotheses: (1) equal survival for released and wild-born individuals with respect to age (i.e. no post-release costs), (2) effect of release method (post-release survival of immatures released by the aviary method differs from hacking-released or wild-born juveniles; method), (3) general reintroduction effect, regardless of the release method (all released individuals suffer from post-release cost on survival compared to wild-born birds (reintro; Table 1). For the method hypothesis we tested whether post-release cost of aviary-released immatures could lead to equal $\left(a^{*}\right.$ method, $\left.s\right)$ or different $\left(a^{*}\right.$ method, $d$ ) survival compared to wild-born or hacking-released black vultures. We only considered short-term release costs of 1 year duration. Black vultures are long-lived scavengers with requirements similar to griffon vultures, in which only 1 year post-release cost affected survival (Sarrazin et al., 1994). Model selection procedure was in two steps by progressively eliminating non-supported hypotheses. In Step 1 we selected the most relevant hypothesis on resighting/recovery and tag loss probabilities (Table 1) using the four following hypotheses on survival: constancy $(i)$, time $(t)$ dependence and the most parameterized hypothesis on survival ( $a^{*}$ method, $\left.d\right)$ and its interaction with time ( $a^{*}$ method, $d^{*} t$; Table 1). In Step 2 we used the most supported resighting/recovery and tag loss hypotheses identified during Step 1 to investigate alternative hypotheses on survival (reintroduction and/or release method effects) and their interactions with time.

\section{Results}

\section{Goodness-of-fit tests}

The goodness-of-fit-live test did not reveal any transience (Test $3 \mathrm{G}$ ) or trap-dependence (Test $\mathrm{M}$ ) for the three groups (all P>0.05, Table 2). For the goodness-of-fit-dead test we pooled groups because the Test $M$ component was not estimable for two groups. The goodness-of-fit-dead was not significant (Global test $\mathrm{M}: \chi^{2}=11.195, \mathrm{df}=8, \mathrm{P}=0.191$ ). Therefore we assumed that the umbrella model $\Phi_{a^{*} \text { method, } d^{*} t}$ $\Psi_{\text {band }}{ }_{\text {age }} \mathrm{P}_{t, \text { both }}$ correctly fitted the data and we used a variance inflation factor $\hat{c}=1$ to compare this model to other models (Pradel, 2005).

Model selection procedure: Step 1, encounter and tag loss probabilities

Within a given survival hypothesis the best supported models always supported $\mathrm{P}_{t \text {,metal }}$ (i.e. resighting rates varied over time for metal bands only, Table 3; sum of wAICc for models assuming this hypothesis $=0.997$ ). Consequently we retained constant plastic band resighting and recovery probabilities and time-dependent metal band resighting probabilities $\left(\mathrm{P}_{t, \text { metal }}\right)$. For tag loss the effect of the banding group $\Psi_{\text {band }}$ was the best supported hypothesis whatever the survival hypothesis considered (models assuming $\Psi_{\text {band }}$ with the lowest AICc score for $\Phi_{i}$ were in rank 5 and for $\Phi_{t}$ rank 9; $\triangle \mathrm{AICC}=3.79$ between models rank 1 and rank 2; sum of $w$ AICc for models assuming $\Psi_{\text {band }}=0.371$; Table 3).

Model selection procedure: Step 2, survival probabilities

We investigated the survival of black vultures with the resighting probability $\mathrm{P}_{t, \text { metal }}$ and the tag loss $\Psi_{\text {band }}$ derived 
TABLE 2 Goodness-of-fit tests of the multi-state resighting data for the Eurasian black vulture (see text for further details).

\begin{tabular}{|c|c|c|c|c|c|c|c|c|c|}
\hline \multirow[b]{2}{*}{ Group $^{*}$} & \multicolumn{3}{|c|}{ Test 3G } & \multicolumn{3}{|c|}{ Test M } & \multicolumn{3}{|c|}{ Global test } \\
\hline & $\chi^{2}$ & $\mathrm{df}$ & $\mathrm{P}$ & $\chi^{2}$ & $\mathrm{df}$ & $\mathrm{P}$ & $\chi^{2}$ & $\mathrm{df}$ & $\mathrm{P}$ \\
\hline Aviary & 7.54 & 20 & 0.99 & 3.69 & 6 & 0.72 & 11.23 & 26 & 0.99 \\
\hline Hacking & 4.67 & 10 & 0.91 & 1.66 & 4 & 0.80 & 6.33 & 14 & 0.96 \\
\hline Wild & 11.77 & 10 & 0.30 & 0.00 & 0 & $\mathrm{NaN}$ & 11.77 & 10 & 0.3 \\
\hline
\end{tabular}

*Aviary group, individuals released by the aviary method; hacking group, individuals released by the hacking method; wild group, wild-born individuals

TABLE 3 Selection of the 10 best models to identify the most likely supported effects on resighting (P) and tag loss probabilities ( $\Psi$ ) for a reduced set of survival pattern $(\Phi)$ of the reintroduced black vultures (Step 1, the selection procedure). We assumed constant recovery probability $(r)$ and therefore this parameter is not included in the model notation. Models with the lowest AICc scores are shown in bold for both the resighting and tag loss probability models. For clarity, we display only the most parameterized tag loss pattern ( $\Psi_{\text {band }}{ }^{\star a g e}$ ) for the resighting probability models and, conversely, only the most parameterized resighting pattern $\left(\mathrm{P}_{\mathrm{t}^{*} \text { metal }}\right)$ for the tag loss probability models.

\begin{tabular}{|c|c|c|c|c|c|c|c|c|}
\hline Rank & Model & & & $\begin{array}{l}\text { No. of } \\
\text { parameters }\end{array}$ & Deviance & $\operatorname{AICc}^{1}$ & $\Delta \mathrm{AICc}^{2}$ & wAICc ${ }^{3}$ \\
\hline \multicolumn{9}{|c|}{ Modelling resighting probabilities } \\
\hline 1 & $\boldsymbol{\Phi}_{a^{\star} \text { method, } d}$ & $\Psi_{\text {band }^{*} \text { age }}$ & $\mathbf{P}_{t, \text { metal }}$ & 22 & 662.15 & 708.96 & & 0.846 \\
\hline 2 & $\Phi_{i}$ & $\Psi_{\text {band*age }}$ & $\mathrm{P}_{t, \text { metal }}$ & 20 & 672.94 & 715.26 & 6.30 & 0.151 \\
\hline 3 & $\Phi_{a^{*} \text { method, } d}$ & $\Psi_{\text {band }}{ }^{*}$ age & $\mathrm{P}_{i}$ & 12 & 693.86 & 718.71 & 9.75 & 0.003 \\
\hline 4 & $\Phi_{i}$ & $\Psi_{\text {band }}{ }^{*}$ age & $\mathrm{P}_{i}$ & 10 & 706.21 & 726.80 & 17.84 & 0.0003 \\
\hline 5 & $\Phi_{a^{*} \text { method, } d}$ & $\Psi_{\text {band*age }}$ & $\mathrm{P}_{t, \text { both }}$ & 37 & 649.04 & 731.16 & 22.22 & $3.6 \mathrm{E}-5$ \\
\hline 6 & $\Phi_{t}$ & $\Psi_{\text {band }}{ }^{*}$ age & $\mathrm{P}_{t, \text { metal }}$ & 35 & 658.14 & 735.38 & 26.42 & $2.1 \mathrm{E}-5$ \\
\hline 7 & $\Phi_{i}$ & $\Psi_{\text {band }}{ }^{*}$ age & $\mathrm{P}_{t, \text { both }}$ & 35 & 659.24 & 736.48 & 27.52 & $8.1 \mathrm{E}-6$ \\
\hline 8 & $\Phi_{a^{*} \text { method, } d}$ & $\Psi_{\text {band*age }}$ & $\mathrm{P}_{t, \text { plastic }}$ & 27 & 680.13 & 738.38 & 29.42 & $4.1 \mathrm{E}-7$ \\
\hline 9 & $\Phi_{t}$ & $\Psi_{\text {band }}{ }^{*}$ age & $\mathrm{P}_{i}$ & 25 & 690.70 & 744.33 & 35.37 & $1.7 \mathrm{E}-7$ \\
\hline 10 & $\Phi_{i}$ & $\Psi_{\text {band }}{ }^{*}$ age & $\mathrm{P}_{t, \text { plastic }}$ & 25 & 692.48 & 746.11 & 37.15 & 0 \\
\hline \multicolumn{9}{|c|}{ Modelling tag loss probabilities } \\
\hline 1 & $\boldsymbol{\Phi}_{a^{*} \text { method,d }}$ & $\Psi_{\text {band }}$ & $\mathbf{P}_{t, \text { metal }}$ & 20 & 662.71 & 705.02 & & 0.357 \\
\hline 2 & $\Phi_{a^{*} \text { method, } d}$ & $\Psi_{i}$ & $\mathrm{P}_{t, \text { metal }}$ & 19 & 668.72 & 708.81 & 3.79 & 0.332 \\
\hline 3 & $\Phi_{a^{*} \text { method, } d}$ & 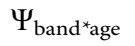 & $\mathrm{P}_{t, \text { metal }}$ & 22 & 662.15 & 708.96 & 3.94 & 0.196 \\
\hline 4 & $\Phi_{a^{*} \text { method, } d}$ & $\Psi_{\text {age }}$ & $\mathrm{P}_{t, \text { metal }}$ & 20 & 667.70 & 710.01 & 4.999 & 0.086 \\
\hline 5 & $\Phi_{i}$ & $\Psi_{\text {band }}$ & $\mathrm{P}_{t, \text { metal }}$ & 18 & 673.78 & 711.66 & 6.64 & 0.014 \\
\hline 6 & $\Phi_{i}$ & 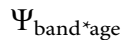 & $\mathrm{P}_{t, \text { metal }}$ & 20 & 672.94 & 715.26 & 10.24 & 0.012 \\
\hline 7 & $\Phi_{i}$ & $\Psi_{i}$ & $\mathrm{P}_{t, \text { metal }}$ & 17 & 679.98 & 715.66 & 10.64 & 0.004 \\
\hline 8 & $\Phi_{i}$ & $\Psi_{\text {age }}$ & $\mathrm{P}_{t, \text { metal }}$ & 18 & 679.69 & 717.56 & 12.54 & $4.7 \mathrm{E}-06$ \\
\hline 9 & $\Phi_{t}$ & $\Psi_{\text {band }}$ & $\mathrm{P}_{t, \text { metal }}$ & 33 & 658.88 & 731.29 & 26.27 & $6.06 \mathrm{E}-07$ \\
\hline 10 & $\Phi_{t}$ & 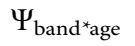 & $\mathrm{P}_{t, \text { metal }}$ & 35 & 658.14 & 735.38 & 30.36 & $5.92 \mathrm{E}-07$ \\
\hline
\end{tabular}

${ }^{1}$ Akaike's information criterion score corrected for small sample sizes

${ }^{2}$ Difference in AICc score between the current model and the best supported model (i.e. rank 1)

${ }^{3}$ AICc weight

from Step 1. Time-dependence $\left(\Phi_{t}, \Phi_{a^{*} t}, \Phi_{a^{*} \text { method, } s^{*} t}\right)$ and release effects $\left(\Phi_{\text {reintro }}\right.$ and $\left.\Phi_{\text {release }}\right)$ were both unlikely to affect survival (model rank from 6 to 10, Table 4). Agespecific survival $\left(\Phi_{a}\right)$ was significantly better supported than the alternative hypothesis of no age effect $\left(\Phi_{i}\right.$; cumulated $w \operatorname{AICc}\left(\Phi_{a}\right)=0.989$ vs $\left.w \operatorname{AICc}\left(\Phi_{i}\right)=0.008\right)$. A post-release cost associated with reintroduction independent of the release method could be rejected ( $\Phi_{a^{*} \text { reintro; }}$ rank 5$)$. Conversely, a short-term effect on survival was detected for immatures released by the aviary method, for both AICc scores $(\triangle \mathrm{AICc}=2.88$ with the second best model supporting no cost on survival $\left.\Phi_{a}\right)$ and $\mathrm{AICc}$ weight $(w \mathrm{AICc}=0.73$;
Table 4). This post-release effect was not a cost in survival $\left(\Phi_{a^{*} \text { method, } d}\right.$ not retained; $w$ AICc $\left.=0.009\right)$ but rather a delayed access to adulthood in terms of survival of immatures released by the aviary method. Wild-born and hacking-released birds reached adult survival at 4 years of age. Thus immatures released from aviaries at a mean age of 2 years should have reached adulthood 2 years after release but they did so after 3 years (Table 5).

Overall, survival rates were high in both immatures and adults, irrespective of the release method (Table 5). From model $\Phi_{a^{*} \text { method,s }} \Psi_{\text {band }} \mathrm{P}_{t, \text { metal }}$ the tag loss probability was c. 4 times higher for coloured than for lettered bands 
TABLE 4 Selection of the 10 best models for survival probability patterns ( $\Phi$; Step 2$)$ for reintroduced black vultures, with resighting (P) and tag loss $(\Psi)$ probabilities retained from Step 1 of the selection procedure (Table 3 ).

\begin{tabular}{|c|c|c|c|c|c|c|c|c|}
\hline Rank & Model & & & $\begin{array}{l}\text { No. of } \\
\text { parameters }\end{array}$ & Deviance & $\mathrm{AICc}^{1}$ & $\Delta \mathrm{AICc}^{2}$ & wAICc $^{3}$ \\
\hline 1 & $\Phi_{a^{\star} \text { method,s }}$ & $\Psi_{\text {band }}$ & $\mathrm{P}_{t, \text { metal }}$ & 19 & 659.92 & 700.01 & & 0.73 \\
\hline 2 & $\Phi_{a}$ & $\Psi_{\text {band }}$ & $\mathrm{P}_{t, \text { metal }}$ & 19 & 662.80 & 702.89 & 2.88 & 0.25 \\
\hline 3 & $\Phi_{a^{*} \text { method, } d}$ & $\Psi_{\text {band }}$ & $\mathrm{P}_{t, \text { metal }}$ & 20 & 662.71 & 705.02 & 5.01 & $9 \mathrm{E}-03$ \\
\hline 4 & $\Phi_{i}$ & $\Psi_{\text {band }}$ & $\mathrm{P}_{t, \text { metal }}$ & 18 & 673.78 & 711.66 & 11.65 & $7.8 \mathrm{E}-03$ \\
\hline 5 & $\Phi_{a^{\star} \text { reintro }}$ & $\Psi_{\text {band }}$ & $\mathrm{P}_{t, \text { metal }}$ & 20 & 669.65 & 711.96 & 11.95 & $3.4 \mathrm{E}-03$ \\
\hline 6 & $\Phi_{\text {reintro }}$ & $\Psi_{\text {band }}$ & $\mathrm{P}_{t, \text { metal }}$ & 19 & 673.50 & 713.58 & 13.57 & $3.1 \mathrm{E}-03$ \\
\hline 7 & $\Phi_{\text {method }}$ & $\Psi_{\text {band }}$ & $\mathrm{P}_{t, \text { metal }}$ & 19 & 673.75 & 713.83 & 13.82 & $4.9 \mathrm{E}-07$ \\
\hline 8 & $\Phi_{t}$ & $\Psi_{\text {band }}$ & $\mathrm{P}_{t, \text { metal }}$ & 33 & 658.88 & 731.29 & 31.28 & $1.2 \mathrm{E}-09$ \\
\hline 9 & $\Phi_{a^{*} t}$ & $\Psi_{\text {band }}$ & $\mathrm{P}_{t, \text { metal }}$ & 46 & 638.41 & 743.24 & 43.23 & $4 \mathrm{E}-10$ \\
\hline 10 & $\Phi_{a^{*} \text { method, } s^{*} t}$ & $\Psi_{\text {band }}$ & $\mathrm{P}_{t, \text { metal }}$ & 45 & 643.27 & 745.55 & 45.54 & 0 \\
\hline
\end{tabular}

${ }^{1}$ Akaike's information criterion corrected for small sample sizes

${ }^{2}$ Difference in AICc score between the current model and the best supported model (i.e. rank 1)

${ }^{3} \mathrm{AICc}$ weight

( $0.11 \pm 0.03$ vs $0.03 \pm 0.02$, respectively). Because of their radio-transmitters the dead-recovery rate of aviary-released immatures was high during the first year after release (0.78 \pm 0.19$)$. Later, the probability of recovering dead birds was reduced ( $0.15 \pm 0.1)$. Plastic bands were easily identifiable $(0.89 \pm 0.02)$ and identification of metal bands varied markedly between years (from o to $0.52 \pm 0.19$; arithmetic mean: $0.2 \pm 0.1$ ).

\section{Discussion}

\section{Survival probabilities and release effects}

Age-specific and high survival in this reintroduced population of the black vulture is consistent with previous findings in natural (Oro et al., 2008) and reintroduced populations of vulture species with similar life history traits (Sarrazin et al., 1994; Le Gouar et al., 2008; Schaub et al., 2009). Survival rates were constant over time and we did not find a difference between juveniles born in the wild and juveniles released by the hacking method. Immatures released from aviaries displayed similar survival rates to juveniles. Consequently the prospect of survival of reintroduced black vultures was similar for the two release methods. However, immatures released from aviaries seemed to suffer from a delay of 1 year in reaching adulthood compared to wild-born and hacking-released juveniles. Overall, post-release effect on immatures was minimal and survival could be seen as equivalent for the two release methods. Nevertheless, there was heterogeneity in age at release in the aviary group, so that adding age at release with time since release may not perfectly match biological ages (Table 5).

Heterogeneity in age at release may have masked any release effects of the aviary method because the survival of
TABLE 5 Survival estimates (mean \pm SE) of black vultures in the Grands Causses (Fig. 1) released by the aviary or hacking method, or born in the wild, from the model averaging in the two best supported models of Step 2 (Table 4 ).

\begin{tabular}{llll}
\hline & \multicolumn{2}{l}{ Released } & \\
\cline { 2 - 3 } Age $^{\star}$ (years) & Aviary & Hacking & Wild born \\
\hline $1-3$ & $0.848 \pm 0.025$ & $0.848 \pm 0.025$ & $0.848 \pm 0.025$ \\
4 & $0.848 \pm 0.026$ & $0.978 \pm 0.018$ & $0.848 \pm 0.026$ \\
$\geqslant 5$ & $0.978 \pm 0.018$ & $0.978 \pm 0.018$ & $0.978 \pm 0.018$ \\
\hline
\end{tabular}

*Aviary-released birds were immatures of mean age 2 years and therefore were on average 5 years-old, with survival similar to adults, during the fourth year after release.

younger birds could buffer the release effect on survival in this group. In addition, the sample size in each release group could have lowered the statistical detection of a post-release cost in survival. We also considered a long (9-month) resighting period, which could potentially bias survival estimates, although this may be of limited importance in such a long-lived species (O'Brien et al., 2005). All wild-born and hacking-released birds fledged between late July and early September, whereas aviary-released birds were released between January and November. Such a heterogeneous survival interval could have, at worst, slightly underestimated survival in the aviary-released group and could partially explain the delay in the access to adulthood. Overall, c. $75 \%$ of aviary releases were conducted between late April and early September, comparable to wild-born or hacking-released birds. Thus heterogeneity in survival interval between groups can be considered as negligible and is unlikely to have affected the results.

We did not detect variation between years in the resighting of plastic bands but rate loss for coloured bands was much higher than for lettered bands. Observations of 
metal bands varied across years, reflecting difficulties in identifications when the plastic band is missing. Without accounting for tag loss c. $10 \%$ of birds may be discarded from capture-recapture histories while still being alive. Our analysis reemphasizes the importance of accounting for tag loss in capture-recapture analyses, to avoid bias in survival estimates (Conn et al., 2004; Le Gouar et al., 2008; Tavecchia et al., 2011).

\section{Comparison of release methods}

Optimal release strategies require maximizing post-release fates of released individuals whilst minimizing logistical requirements. Dispersal may greatly decrease apparent survival at a release site, either through emigration or by inducing increased mortality because of high mobility. Reintroductions focused on species or taxa with high dispersal abilities (e.g. mammals or birds; Seddon et al., 2005) and post-release movements are a major cause of reintroduction failure (Le Gouar et al., 2011). Soft releases generally involve extended pre-release (e.g. an imprinting period) and post-release care (e.g. supplementary food) to enhance survival and settlement at the release site and are thus more expensive and time consuming than hard releases. The latter are often associated with a short-term reduction in post-release survival because of the inexperience of captive-born individuals, either resulting in extra-dispersal or mortality (e.g. in Sandhill Cranes Grus Canadensis; Nagendran et al., 1996). Regarding contextdependent logistical or financial constraints associated with each method, both the aviary and hacking methods could equally be used for immatures and juveniles.

Age-related physiological and behavioural features may influence survival or dispersal (Le Gouar et al., 2008) and these specificities have to be adequately accounted for in defining a release strategy. Adults may be negatively affected by long-term captivity and thus experience increased mortality in the first year following release. In raptors the aviary method for releasing adults can have a cost in survival (e.g. griffon vultures; Sarrazin et al., 1994), whereas the survival of hacking-released juveniles may be similar to that of wildborn individuals in both long-lived (e.g. red kites, Evans et al., 1999; griffon vultures, Sarrazin et al., 1994) and shortlived species (e.g. Mauritius kestrels; Nicoll et al., 2004). However, releasing individuals of high reproductive value, such as adults or immatures, may be beneficial when generation time is long, to generate the production of wildborn offspring as soon as possible (Robert et al., 2002). Juveniles may lack mentors to learn how to survive in the wild. Post-release costs in survival have been reported in the hacking of juveniles of the Aplomado falcon Falco Femoralis septentrionalis (Brown et al., 2006) and in the long-lived white-tailed eagle Haliaeetus albicilla (Evans et al., 2009).
Similarly, a third of juvenile crested coots Fulica cristata released from large aviaries died within the first month (Tavecchia et al., 2009). However, even if age at release is important it is not always possible to manage the age of the individuals available.

Hacking may be as suitable for the release of juveniles as aviary-release for immatures in long-lived scavengers such as vultures. However, this conclusion could partly rely on the context of our study. Independently of release method and life-history traits, external mechanisms such as dispersal because of conspecific attraction may have strong effects on survival and settlement (Mihoub et al., 2011), as reported for reintroduced griffon vultures (Le Gouar et al., 2008). The reintroduction of black vultures in the Grands Causses occurred in the absence of a conspecific population in the release area but a griffon vulture population may have promoted the settlement of released black vultures. The apparently high survival of black vultures may reflect both their ability to survive and low emigration related to the presence of griffon vultures acting as a heterospecific attraction (Hromada et al., 2008).

\section{Monitoring}

Long-term monitoring is required to document and evaluate reintroduction projects (Sarrazin \& Barbault, 1996; Sutherland et al., 2010). Survival estimated from translocated individuals that have faced circumstances leading to possible decrease in post-release apparent survival (e.g. enhanced mortality or dispersal) provide more realistic estimates than estimates from natural populations (Sarrazin \& Barbault, 1996; Sarrazin \& Legendre, 2000; Mihoub et al., 2009, 2011). In addition to comparing release methods, estimating survival of reintroduced animals is crucial for identifying potential threats in the wild (Ewen \& Armstrong, 2007). Most threats to vultures are a result of human activities or effects such as land-use change or poisoning of carcasses (Virani et al., 2011), wind farms (Carrete et al., 2009), lethal exposure to drugs (Green et al., 2004) and junk food (Houston et al., 2007). In the Grands Causses the survival of black vultures suggests that these threats are not currently present but continuous monitoring is nevertheless required.

\section{Acknowledgements}

The monitoring of the population has been conducted by the Ligue Protectrice des Oiseaux-Mission Rapaces, the Parc National des Cévennes and many volunteers. The Ligue Protectrice des Oiseaux-Mission Rapaces initiated the release of black vultures. We particularly thank Michel Terrasse for his personal involvement in scavenger 
recovery in France and Europe. Financial support was provided by the National Restoration Plan for the black vulture and by the French Ministry of Research. We dedicate this article to the memory of our friend and colleague Bertand Eliotout, who died tragically in a car accident in 2009.

\section{References}

Armstrong, D.P. \& Seddon, P.J. (2008) Directions in reintroduction biology. Trends in Ecology and Evolution, 23, 20-25.

B ARKER, R.J. (1997) Joint modeling of live-recapture, tag-resight, and tag-recovery data. Biometrics, 53, 666-677.

Birdife International (2012) Aegypius monachus. In IUCN Red List of Threatened Species v. 2013.1. Http://www.iucnredlist.org [accessed 24 September 2013].

Bose, M., Le Gouar, P., Arthur, C., Larnbourdiere, J., Choisy, J.P., Henriquet, S. et al. (2007) Does sex matter in reintroduction of griffon vultures Gyps fulvus? Oryx, 41, 503-508.

Brown, J.L., Collopy, M.W., Gott, E.J., Juergens, P.W., Montoya, A.B. \& Hunt, W.G. (2006) Wild-reared aplomado falcons survive and recruit at higher rates than hacked falcons in a common environment. Biological Conservation, 131, 453-458.

Burnham, K.P. \& Anderson, D.R. (2002) Model Selection and Multimodel Inference: A Practical Information-Theoretic Approach. Springer, New York, USA.

Carrete, M., Sánchez-Zapata, J.A., Benitez, J.R., Lobon, M. \& DONÁZAR, J.A. (2009) Large scale risk-assessment of wind-farms on population viability of a globally endangered long-lived raptor. Biological Conservation, 142, 2957-2961.

Choquet, R., Reboulet, A.-M., Lebreton, J.-D., Gimenez, O. \& Pradel, R. (2005) U-CARE 2.2 User Manual. CEFE, Montpellier, France.

Choquet, R., Rouan, L. \& Pradel, R. (2008) Program E-SURGE: a software application for fitting multievent models. Environmental and Ecological Statistics, 3, 847-868.

Conn, P.B., Kendall, W.L. \& SAmuel, M.D. (2004) A general model for the analysis of mark-resight, mark-recapture, and bandrecovery data under tag loss. Biometrics, 60, 900-909.

del Hoyo, J., Elliot, A. \& Sargatal, J. (1996) Handbook of the Birds of the World Volume 2: New World Vultures to Guineafowl (eds J. del Hoyo, A. Elliott \& J. Sargatal), pp. 52-205. Lynx Edicions, Barcelona, Spain.

Duriez, O., Ens, B.J., Choquet, R., Pradel, R. \& Klaassen, M. (2012) Comparing the seasonal survival of resident and migratory oystercatchers: carry-over effects of habitat quality and weather conditions. Oikos, 121, 862-873.

Duriez, O., Saether, B.E., Ens, B.J., Choquet, R., Pradel, R., Lambeck, R.H.D. \& KlaAssen, M. (2009) Estimating survival and movements using both live and dead recoveries: a case study of oystercatchers confronted with habitat change. Journal of Applied Ecology, 46, 144-153.

Dzialak, M.R., Lacki, M.J., Carter, K.M., Huie, K. \& Cox, J.J. (2006) An assessment of raptor hacking during a reintroduction. Wildlife Society Bulletin, 34, 542-547.

Evans, I.M., Summers, R.W., O’Toole, L., Orr-Ewing, D.C., Evans, R., SNELL, N. \& SMith, J. (1999) Evaluating the success of translocating red kites Milvus milvus to the UK. Bird Study, 46, 129-144.

Evans, R.J., Wilson, J.D., Amar, A., Douse, A., MacLennan, A., Ratcliffe, N. \& Whitfield, D.P. (2009) Growth and demography of a re-introduced population of white-tailed eagles Haliaeetus albicilla. Ibis, 151, 244-254.

Ewen, J.G. \& Armstrong, D.P. (2007) Strategic monitoring of reintroductions in ecological restoration programmes. Ecoscience, 14, 401-409.

Green, R.E., Newton, I., Shultz, S., Cunningham, A.A., Gilbert, M., Pain, D.J. \& Prakash, V. (2004) Diclofenac poisoning as a cause of vulture population declines across the Indian subcontinent. Journal of Applied Ecology, 41, 793-800.

Grosbois, V. \& Tavecchia, G. (2003) Modeling dispersal with capture-recapture data: disentangling decisions of leaving and settlement. Ecology, 84, 1225-1236.

Hardman, B. \& Moro, D. (2006) Optimising reintroduction success by delayed dispersal: is the release protocol important for hare-wallabies? Biological Conservation, 128, 403-411.

Houston, D.C., Mee, A. \& McGrady, M. (2007) Why do condors and vultures eat junk?: The implications for conservation. Journal of Raptor Research, 41, 235-238.

Hromada, M., Antczak, M., Valone, T.J. \& Tryjanowski, P. (2008) Settling decisions and heterospecific social information use in shrikes. PLoS ONE, 3, e3930.

Kendall, W.L., Conn, P.B. \& Hines, J.E. (2006) Combining multistate capture-recapture data with tag recoveries to estimate demographic parameters. Ecology, 87, 169-177.

Le Gouar, P., Minoub, J.-B. \& Sarrazin, F. (2011) Dispersal and habitat selection: behavioural and spatial constraints for animal translocations. In Reintroduction Biology: Integrating Science and Management (eds J.G. Ewen, D.P. Armstrong, K.A. Parker \& P.J. Seddon), pp. 138-164. Wiley-Blackwell Publishing, Oxford, UK.

Le Gouar, P., Robert, A., Choisy, J.P., Henriquet, S., Lecuyer, P., Tessier, C. \& Sarrazin, F. (2008) Roles of survival and dispersal in reintroduction success of griffon vulture (Gyps fulvus). Ecological Applications, 18, 859-872.

Lebreton, J.-D., Burnham, K.P., Clobert, J. \& Anderson, D.R. (1992) Modeling survival and testing biological hypothesis using marked animals: a unified approach with case studies. Ecological Monographs, 62, 67-118.

Lebreton, J.-D. \& Clobert, J. (1991) Bird population dynamics, management and conservation: the role of mathematical modelling. In Bird Population Studies: Relevance to Conservation and Management (eds C.M. Perrins, J.-D. Lebreton \& G.J.M. Hirons), pp. 105-125. Oxford University Press, Oxford, UK.

Lebreton, J.-D. \& Pradel, R. (2002) Multistate recapture models: modelling incomplete individual histories. Journal of Applied Statistics, 29, 353-369.

Minoub, J.-B., Le Gouar, P. \& Sarrazin, F. (2009) Breeding habitat selection behaviors in heterogeneous environments: Implications for modeling reintroduction. Oikos, 118, 663-674.

Minoub, J.-B., Robert, A., Le Gouar, P. \& Sarrazin, F. (2011) Post-release dispersal in translocation: social attraction and the "vacuum effect". PLoS ONE, 6, e27453.

Nagendran, M., Urbanek, R.P. \& Ellis, D.H. (1996) Reintroduction techniques. In Cranes: Their biology, Husbandry and Conservation (eds D.H. Ellis, G.F. Gee \& C.M. Mirande), pp. 231-240. Hancock House Publishers, Blaine, USA.

Nich OLS, J.D. (1992) Capture-recapture models using marked animals to study population dynamics. Bioscience, 42, 94-102.

Nicoll, M.A.C., Jones, C.G. \& Norris, K. (2004) Comparison of survival rates of captive-reared and wild-bred Mauritius kestrels (Falco punctatus) in a re-introduced population. Biological Conservation, $118,539-548$.

O’Brien, S.J.O., Bourou, R. \& Hafany, T. (2005) Consequences of violating the recapture duration assumption of mark-recapture 
models: a test using simulated and empirical data from an endangered tortoise population. Journal of Applied Ecology, 42, 1046-1104.

Oro, D., Margalida, A., Carrete, M., Heredia, R. \& DonaZAR, J.A. (2008) Testing the goodness of supplementary feeding to enhance population viability in an endangered vulture. PLOS ONE, 3, e4084.

Pradel, R. (2005) Multievent: an extension of multistate capture-recapture models to uncertain states. Biometrics, 61, 442-447.

Pradel, R., Gimenez, O. \& Lebreton, J.-D. (2005) Principles and interest of GOF tests for multistate capture-recapture models. Animal Biodiversity and Conservation, 28, 189-204.

Robert, A., Couvet, D. \& Sarrazin, F. (2002) Fitness heterogeneity and viability of restored populations. Animal Conservation, 5 , 153-161.

SARRAZIN, F. (2007) Introductory remarks-a demographic frame for reintroductions. Ecoscience, 14, IV-V.

Sarrazin, F., Bagnolini, C., Pinna, J.-L., Danchin, E. \& Clobert, J. (1994) High survival estimates of Griffon Vultures (Gyps fulvus fulvus) in a reintroduced population. Auk, $111,853-862$.

Sarrazin, F. \& Barbault, R. (1996) Reintroduction: challenges and lessons for basic ecology. Trends in Ecology and Evolution, 11, $474-478$.

Sarrazin, F. \& Legendre, S. (2000) Demographic approach to releasing adults versus young in reintroductions. Conservation Biology, 14, 488-500.

Schaub, M., Zink, R., Beissmann, H., Sarrazin, F. \& Arlettaz, R (2009) When to end releases in reintroduction programmes: demographic rates and population viability analysis of bearded vultures in the Alps. Journal of Applied Ecology, 46, 92-100.

Seddon, P.J., Soorae, P.S. \& Launay, F. (2005) Taxonomic bias in reintroduction projects. Animal Conservation, 8, 51-58.
Sutherland, W.J., Armstrong, D., Butchart, S.H.M., Earnhardt, J., Ewen, J.G., Jamieson, I. et al. (2010) Standards for documenting and monitoring bird reintroduction projects.

Conservation Letters, 3, 229-235.

Tavecchia, G., Adrover, J., Navarro, A.M. \& Pradel, R. (2011) Modelling mortality causes in longitudinal data in the presence of tag loss: application to raptor poisoning and electrocution. Journal of Applied Ecology, 49, 297-305.

Tavecchia, G., Viedma, C., Martinez-Abrain, A., Bartolome, M.A., Gomez, J.A. \& Oro, D. (2009) Maximizing re-introduction success: assessing the immediate cost of release in a threatened waterfowl. Biological Conservation, 142, 3005-3012.

Virani, M.Z., Kendall, C., Njoroge, P. \& Thomsett, S. (2011) Major declines in the abundance of vultures and other scavenging raptors in and around the Masai Mara ecosystem, Kenya. Biological Conservation, 144, 746-752.

Wolf, M.C., Griffith, B., Reed, C. \& Temple, S.A. (1996) Avian and mammalian translocations: update and reanalysis of 1987 survey data. Conservation Biology, 10, 1142-1154.

\section{Biographical sketches}

Jean-Baptiste Minoub's research activities mainly focus on demography and animal behaviour with respect to translocations. KARINE PRINCE is carrying out research on the conservation of farmland birds. Olivier Duriez's research focuses on the integration of behavioural ecology and demography in the conservation biology of birds, particularly raptors. PHILIPPE LÉCUYER and Bertrand Eliotout have played key roles in the reintroduction and monitoring of vultures in the Grands Causses. FrançOIs SARRAZIN carries out research on reintroduction biology and has been involved in the recovery of vultures in France for more than 20 years. 